\title{
The milk-derived peptides Val-Pro-Pro and lle-Pro-Pro attenuate arterial dysfunction in L-NAME-treated rats
}

\author{
Atsuko Nonaka ${ }^{1}$, Teppei Nakamura ${ }^{1}$, Tatsuhiko Hirota ${ }^{1}$, Akiko Matsushita ${ }^{1}$, Masanori Asakura ${ }^{2}$, Kohji Ohki ${ }^{1}$ \\ and Masafumi Kitakaze ${ }^{2}$
}

Both endothelial dysfunction and arterial stiffness are surrogate markers of atherosclerosis and thus cardiovascular (CV) events. The milk-derived peptides Val-Pro-Pro (VPP) and lle-Pro-Pro (IPP) inhibit angiotensin-converting enzyme, dilate blood vessels ex vivo and stimulate nitric oxide (NO) production in cells. In this study, we investigated the effects of either VPP or IPP on arterial function and on target organ damage in vivo. Male Wistar rats were treated with N(G)-nitro-L-arginine methyl ester hydrochloride (L-NAME, $\left.1 \mathrm{~g} \mathrm{I}^{-1}\right)$, L-NAME + VPP $\left(0.3 \mathrm{gl}^{-1}\right)$ or L-NAME + IPP $\left(0.3 \mathrm{gl}^{-1}\right)$ in their drinking water for 8 weeks. Plasma nitrite and nitrate (NOx) levels were significantly increased in normal Wistar rats after supplementation with either VPP or IPP but not in rats that were chronically treated with L-NAME. Acetylcholine-induced vasorelaxation in the thoracic aorta ring was impaired by L-NAME, whereas vasorelaxation was significantly greater in mice treated with L-NAME + VPP for 1 or 4 weeks or L-NAME + IPP for 4 weeks than in mice treated with L-NAME alone. Four weeks of treatment with either VPP or IPP attenuated the increase in pulse wave velocity (PWV) that was induced by L-NAME. Cardiac and renal damage were observed after 8 weeks of treatment with L-NAME, and either VPP or IPP attenuated this damage. These results show that VPP or IPP attenuates arterial dysfunction and suggest that milk-derived peptides might prevent $\mathrm{CV}$ damage.

Hypertension Research (2014) 37, 703-707; doi:10.1038/hr.2014.72; published online 3 April 2014

Keywords: arterial stiffness; endothelial dysfunction; Ile-Pro-Pro; L-NAME; Val-Pro-Pro

\section{INTRODUCTION}

Endothelial dysfunction is known to be the common pathophysiological route of cardiovascular $(\mathrm{CV})$ risk factors progressing to $\mathrm{CV}$ disease and thus to $\mathrm{CV}$ events. ${ }^{1}$ Arterial stiffness, measured by pulse wave velocity (PWV), also provides a predictive value for future $\mathrm{CV}$ events and mortality. ${ }^{2,3}$ Lifestyle-related diseases, such as hypertension, diabetes and dyslipidemia, are primary risk factors for $\mathrm{CV}$ diseases, and many reports show that the treatment of these diseases with drugs improves endothelial function ${ }^{4}$ and arterial stiffness, ${ }^{2,3}$ and reduces CV events. ${ }^{3}$ In addition, there is great interest in the effects of non-pharmaceutical interventions on $\mathrm{CV}$ diseases, as some dietary and nutrient interventions improve endothelial function ${ }^{1}$ and arterial stiffness. ${ }^{2,5}$

Val-Pro-Pro (VPP) and Ile-Pro-Pro (IPP) are milk-derived peptides with inhibitory activity against angiotensin-converting enzyme (ACE). ${ }^{6}$ These peptides have been shown to decrease blood pressure in spontaneously hypertensive rats $(\mathrm{SHR})^{7}$ and attenuate the development of atherosclerosis in apolipoprotein E-deficient $(\operatorname{apoE}(-/-))$ mice. $^{8}$ In addition, VPP and IPP increased nitric oxide (NO) production in human umbilical vein endothelial cells (HUVECs) and had an endothelium-dependent vasodilatory effect in ex vivo assays. ${ }^{9}$ Moreover, in several clinical trials, foods containing these peptides improved vascular endothelial function ${ }^{10}$ and arterial stiffness. ${ }^{11}$ These findings suggest that administration of VPP or IPP improves CV health, but there is very little evidence regarding the individual in vivo effects of VPP and IPP on arterial function.

$\mathrm{NO}$ is a primary vascular regulatory factor that has vasoprotective effects, such as vasodilation, inhibition of platelet aggregation and inhibition of smooth muscle proliferation. ${ }^{12} \mathrm{~N}(\mathrm{G})$-nitro-L-arginine methyl ester hydrochloride (L-NAME) is an analog of L-arginine and a competitive inhibitor of NO synthase (NOS). ${ }^{13}$ Chronic administration of L-NAME causes arterial hypertension associated with left ventricular remodeling and renal injury ${ }^{14}$ and has also proven to be a useful model for endothelial dysfunction ${ }^{15,16}$ and arterial stiffness. ${ }^{17,18}$ Therefore, the aim of this study was to investigate the effects of VPP and IPP on arterial function and target organ damage in L-NAME-treated rats.

\section{METHODS}

Animals

For this study, 7-week-old male Wistar rats were obtained from Japan SLC (Shizuoka, Japan) and acclimatized in a room with controlled temperature $\left(23^{\circ} \mathrm{C}\right)$, humidity $(55 \%)$ and lighting (12:12-h light-dark cycle) with access to a commercial diet (CE-2; CLEA Japan, Tokyo, Japan) and tap water ad libitum for 1 week. All animal experiments were conducted in accordance with the 'Guidelines for Animal Experimentation of the Japanese Association for

${ }^{1}$ Microbiology \& Fermentation Laboratory, Calpis Co., Ltd., Kanagawa, Japan and ${ }^{2}$ Department of Clinical Medicine and Development, National Cerebral and Cardiovascular Center, Suita, Japan

Correspondence: T Nakamura, Microbiology \& Fermentation Laboratory, Calpis Co., Ltd., 5-11-10 Fuchinobe, Chuo-ku, Sagamihara, Kanagawa 252-0206, Japan. E-mail: teppei.nakamura@calpis.co.jp

Received 24 October 2013; revised 5 December 2013; accepted 12 December 2013; published online 3 April 2014 
Laboratory Animal Science' and were approved by the Animal Experiment Committee of Calpis.

\section{Experimental groups}

Rats were randomly divided into four groups based on body weight. The first group (control) received untreated drinking water. The second group (L-NAME) received L-NAME $\left(1 \mathrm{gl}^{-1}\right.$, approximately $100 \mathrm{mg} \mathrm{kg}^{-1}$ per day, Sigma-Aldrich, Tokyo, Japan) dissolved in drinking water. The dose of L-NAME was determined based on the methods of a previous report that demonstrated cardiac remodeling in rats. ${ }^{19}$ The third group (L-NAME + VPP) received L-NAME $\left(1 \mathrm{gl}^{-1}\right)$ and VPP $\left(0.3 \mathrm{gl}^{-1}\right.$, approximately $30 \mathrm{mg} \mathrm{kg}^{-1}$ per day, Bachem, CA, USA). The fourth group (L-NAME + IPP) received L-NAME $\left(1 \mathrm{gl}^{-1}\right)$ and IPP $\left(0.3 \mathrm{gl}^{-1}\right.$, approximately $30 \mathrm{mg} \mathrm{kg}^{-1}$ per day, Bachem) for 8 weeks.

\section{Acetylcholine-induced vasorelaxation}

After 1 week and 4 weeks of treatment, the rats ( $n=5-9 /$ group) were anesthetized with diethyl ether, and the thoracic aortae were isolated. To prepare aortic rings, thoracic aortae were cut into 2-3-mm lengths after the removal of adherent tissue. The prepared aortic rings were attached to a micro tissue organ bath (MTOB-1, LAB Support, Osaka, Japan) filled with prewarmed Tyrode's solution $\left(10 \mathrm{mmoll}^{-1} \mathrm{NaHCO}_{2}, 5.0 \mathrm{mmoll}^{-1}\right.$ glucose, $158.3 \mathrm{mmoll}^{-1} \mathrm{NaCl}, \quad 4.0 \mathrm{mmoll}^{-1} \mathrm{KCl}, \quad 2.0 \mathrm{mmoll}^{-1} \quad \mathrm{CaCl}_{2}-2 \mathrm{H}_{2} \mathrm{O}$, $\left.1.0 \mathrm{mmoll}^{-1} \mathrm{MgCl}_{2}-6 \mathrm{H}_{2} \mathrm{O}, 0.42 \mathrm{mmoll}^{-1} \mathrm{NaH}_{2} \mathrm{PO}_{4}\right)$ at $37^{\circ} \mathrm{C}$ and bubbled with $95 \% \mathrm{O}_{2}+5 \% \mathrm{CO}_{2}$ gas. The aortic ring was loaded to $2 \mathrm{~g}$ of initial tension and contracted by adding phenylephrine (Sigma-Aldrich) at a final concentration of $1 \mu \mathrm{moll}^{-1}$ after the tension was stabilized. After sufficient contraction with phenylephrine, $1-10 \mu \mathrm{moll}^{-1}$ acetylcholine (Sigma-Aldrich) was incrementally applied to the bath, and the degree of relaxation was determined by the tension change to the phenylephrine-induced contraction.

\section{Measurement of PWV and blood pressure}

After 1 week and 4 weeks of treatment, the rats ( $n=6-9 /$ group) were anesthetized with isoflurane and placed on a heating board at $37^{\circ} \mathrm{C}$ to maintain body temperature. Measurements of both PWV and blood pressure were conducted using a Millar Mikro-tip pressure transducer (2.5Fr, SPC-721 Millar Instruments, Houston, TX, USA) with dual high-fidelity pressure sensors: one located at the distal end and the other located $50 \mathrm{~mm}$ away. The sensors were inserted via the left carotid artery into the aortic arch and abdominal aorta. When the arterial pressure and heart rate were stable, the pressure waves were recorded for at least $30 \mathrm{~min}$. The signals were digitized and stored using a data acquisition system (PowerLab, ADInstruments, Castle Hill, NSW, Australia). The transit time of the pressure wave moving from the aortic arch to the abdominal aorta was obtained from the time difference between the two recording sites. At least 10 normal consecutive cardiac cycles were used and averaged for a measurement. PWV was calculated from the transit time and the distance between the two recording sites $(50 \mathrm{~mm})$. Blood pressure was calculated from the proximal pressure wave by using the data acquisition system. Furthermore, blood samples were collected for measurements of plasma levels of NOx (nitrite and nitrate).

\section{Plasma NOx}

We measured the plasma NOx concentration in rats treated with L-NAME and in nontreated (that is, normal Wistar) rats ( $n=6-9 /$ group) before and $2 \mathrm{~h}$ after a single oral administration of VPP or IPP at $0.1,1$ or $10 \mathrm{mg} \mathrm{kg}^{-1}$ body weight. Plasma NOx concentration was measured using a commercially available kit $\left(\mathrm{NO}_{2} / \mathrm{NO}_{3}\right.$ Assay Kit-FX, Dojindo, Kumamoto, Japan).

\section{Histological examination}

After 8 weeks of treatment, the rats ( $n=6-12 /$ group) were anesthetized with diethyl ether before the heart and kidney were isolated. The tissues were fixed with $10 \%$ neutral buffered formalin $(\mathrm{pH} 7.4)$ and embedded in paraffin. A 2- $\mu \mathrm{m}$-thick cross-section from each paraffin block was stained with hematoxylin-eosin (HE) for the heart or periodic acid-methenamine-silver
(PAM) stain for the kidney. The histological evaluation was performed in a blinded manner by an external pathologist.

\section{Statistical analysis}

Data are expressed as the means \pm s.e. We used two-way repeated measure analysis of variance (ANOVA) for the acetylcholine-induced vasorelaxation and one-way ANOVA with Dunnett's test for the other parameters. Statistical significance was defined as $P<0.05$ by a two-tailed test. Statistical analysis was performed using IBM SPSS Statistics version 20 (IBM, Tokyo, Japan).

\section{RESULTS}

\section{Plasma NOx}

After 4 weeks of treatment, the mean concentration of NOx in the plasma of control mice was $10.9 \pm 1.7 \mu \mathrm{moll}^{-1}$, which is significantly higher than the value of $3.6 \pm 0.3 \mu \mathrm{moll}^{-1}$ measured in rats from the L-NAME group. The concentrations of NOx in the rats from the L-NAME + VPP and L-NAME + IPP groups were $3.9 \pm 0.6$ and $3.7 \pm 0.8 \mu \mathrm{moll}^{-1}$, respectively, which were not significantly different from the concentration in the L-NAME group. The concentrations after 1 week of treatment were similar to those after 4 weeks of treatment (data not shown). Figure 1 shows plasma NOx concentrations relative to the values before administration of VPP or IPP in normal Wistar rats. Relative NOx concentrations were $153.2 \pm 20.7 \%$ $(P<0.05)$ at $0.1 \mathrm{mg} \mathrm{kg}^{-1} \mathrm{VPP}$ and $155.3 \pm 23.9 \% \quad(P<0.05)$ at $10 \mathrm{mg} \mathrm{kg}^{-1} \mathrm{VPP}$, and were significantly higher than the value of $85.6 \pm 13.4 \%$ in the control group. The concentrations of NOx after $0.1,1$ and $10 \mathrm{mg} \mathrm{kg}^{-1}$ IPP administration were $94.1 \pm 14.7 \%$ (not significant; NS), $147.2 \pm 19.0 \% \quad$ (NS) and $217.1 \pm 57.4 \%$ $(P<0.05$ vs. control group), respectively.

\section{Acetylcholine-induced vasorelaxation}

Figure 2 shows the effects of oral administration of VPP or IPP on acetylcholine-induced vasorelaxation of the thoracic aorta in L-NAME-treated rats. In rats treated with L-NAME for 1 week, the maximal relaxation after administration of $10 \mu \mathrm{moll}^{-1}$ acetylcholine was $26.1 \pm 3.9 \%$ in the L-NAME group, whereas the responses in the control, L-NAME + VPP and L-NAME + IPP groups were $92.4 \pm 5.6 \%(P<0.001$ vs. L-NAME group $), 43.1 \pm 4.1 \%(P<0.001)$
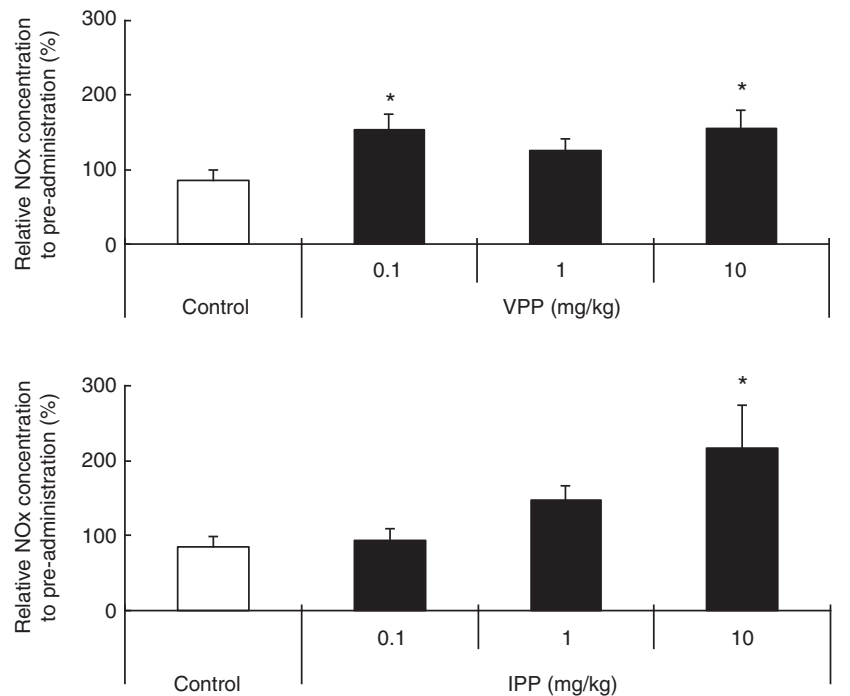

Figure 1 The influence of VPP and IPP on NOx production in normal Wistar rats $2 \mathrm{~h}$ after a single oral administration. Data are presented as the mean \pm s.e. ${ }^{*} P<0.05$ vs. control group. 

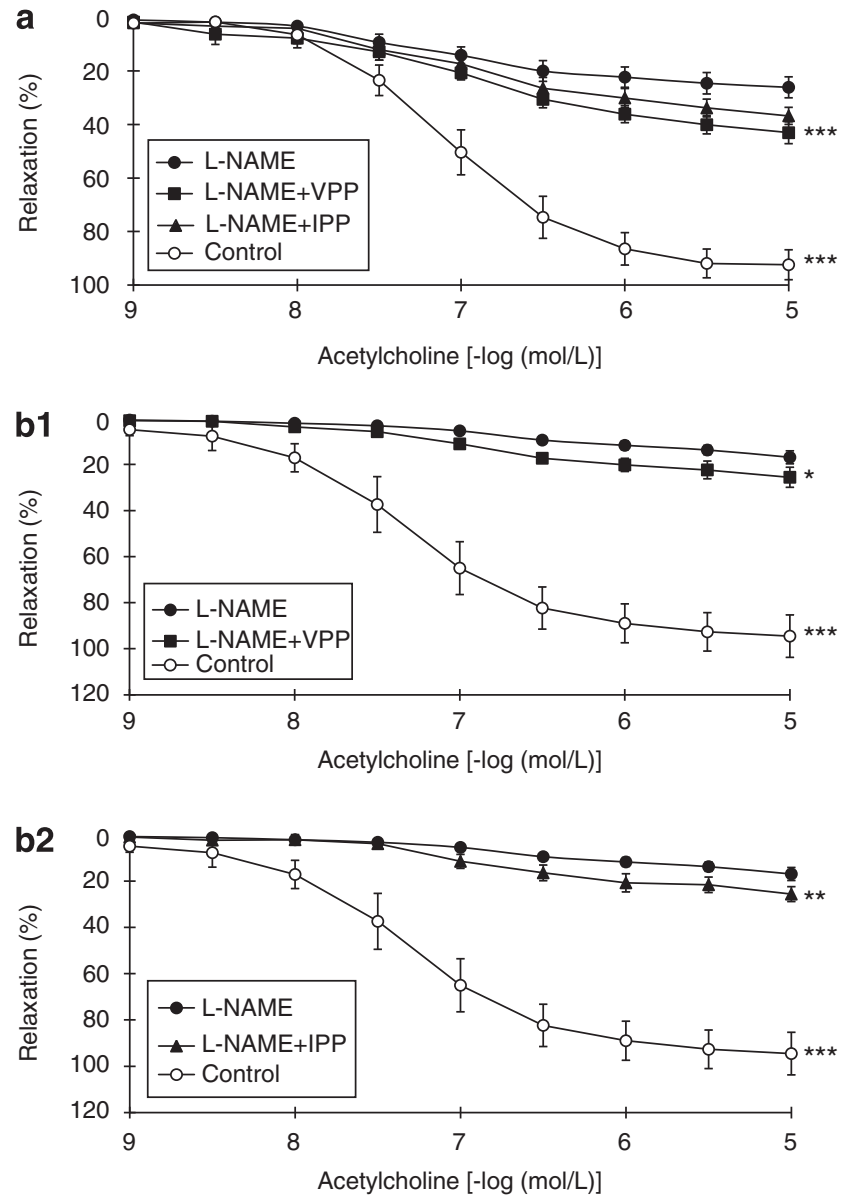

Figure 2 The influence of VPP and IPP on vascular responses to acetylcholine in the thoracic aorta in rats treated with L-NAME for 1 week (a) and 4 weeks $\left(\mathbf{b} 1\right.$, b2). Data are shown as the mean \pm s.e. ${ }^{*} P<0.05$, ${ }^{* *} P<0.01,{ }^{* *} P<0.001$ vs. L-NAME group.

and $36.8 \pm 3.2 \%(P=0.067)$, respectively. After 4 weeks of treatment, the maximal relaxation was $16.9 \pm 2.8 \%$ in the L-NAME group, and the responses in the control $(94.5 \pm 7.5 \%, P<0.001)$, L-NAME + VPP $(25.5 \pm 4.4 \%, P<0.05)$ and L-NAME + IPP $(25.6 \pm 3.2 \%, P<0.01)$ groups were significantly higher than that in the L-NAME group.

\section{PWV}

PWV did not differ after 1 week of treatment among the rats in the L-NAME, L-NAME + VPP and L-NAME + IPP groups with values of $460.0 \pm 4.0, \quad 480.3 \pm 30.1$ and $447.3 \pm 11.0 \mathrm{~cm} \mathrm{~s}^{-1}, \quad$ respectively. Figure 3 shows PWV in rats after 4 weeks of treatment. PWV in the control group was $344.4 \pm 13.9 \mathrm{~cm} \mathrm{~s}^{-1}$, which was significantly lower $(P<0.001)$ than the value of $572.9 \pm 31.5 \mathrm{~cm} \mathrm{~s}^{-1}$ that in the $\mathrm{L}-$ NAME group. PWV values in the L-NAME + VPP and L-NAME + IPP groups were $456.4 \pm 27.3(P<0.05)$ and $473.6 \pm 28.1 \mathrm{~cm} \mathrm{~s}^{-1}$ $(P<0.01)$, respectively, which were significantly lower than that in the L-NAME group.

\section{Blood pressure and heart rate}

Table 1 shows the blood pressures and heart rates in rats treated with L-NAME for 4 weeks. Systolic blood pressure, diastolic blood pressure and pulse pressure were significantly lower in the control group than that in the L-NAME group. There were no significant differences in these parameters for the L-NAME + VPP and L-NAME + IPP groups

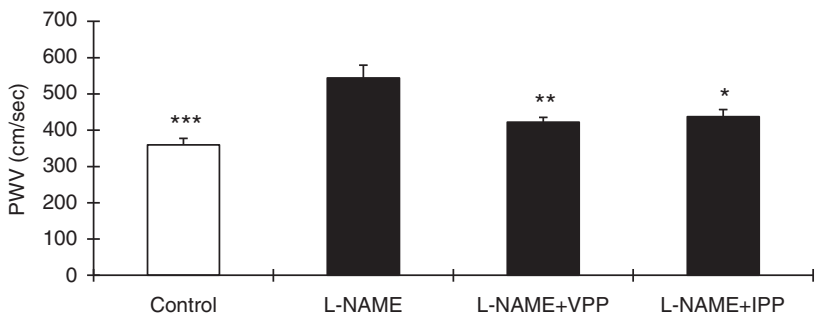

Figure 3 The influence of VPP and IPP on pulse wave velocity (PWV) in rats treated with L-NAME for 4 weeks. Data are presented as the mean \pm s.e. ${ }^{*} P<0.05,{ }^{* *} P<0.01,{ }^{* *} P<0.001$ vs. L-NAME group.

Table 1 Blood pressure and heart rate in L-NAME-treated rats at 4 weeks

\begin{tabular}{lcrcc}
\hline & Control & L-NAME & L-NAME +VPP & L-NAME + IPP \\
\hline SBP (mm Hg) & $111.7 \pm 5.5^{* * *}$ & $158.4 \pm 6.6$ & $154.3 \pm 6.2$ & $156.6 \pm 5.9$ \\
DBP (mm Hg) & $78.0 \pm 4.4^{* * *}$ & $115.6 \pm 4.0$ & $115.0 \pm 5.7$ & $117.2 \pm 5.1$ \\
PP (mm Hg) & $33.8 \pm 1.3^{*}$ & $42.9 \pm 2.9$ & $39.4 \pm 1.9$ & $39.4 \pm 1.4$ \\
HR (b.p.m.) & $299.8 \pm 26.9$ & $326.1 \pm 9.4$ & $306.8 \pm 11.0$ & $328.7 \pm 17.7$
\end{tabular}

Abbreviations: $\mathrm{DBP}$, diastolic blood pressure; $\mathrm{HR}$, heart rate; $\mathrm{PP}$, pulse pressure; $\mathrm{SBP}$, systolic blood pressure. Data are mean \pm s.e. ${ }^{*} P<0.05,{ }^{* * *} P<0.001$ vs. L-NAME group.

compared with the L-NAME group. The results after 1 week of treatment were similar to those after 4 weeks of treatment (data not shown).

\section{Histological examination}

Figure 4 shows representative sections of the heart and kidney from rats treated with L-NAME for 8 weeks. Microscopic examination revealed that treatment with L-NAME promoted left ventricular hypertrophy and abnormal morphology of the renal glomerulus and increased wall thickness of the small-to-medium-sized arteries of the kidney. All of these measurements were lower in the L-NAME + VPP group. In the L-NAME + IPP group, only the wall thickness of the small-to-medium-sized arteries of the kidney was decreased.

\section{DISCUSSION}

We investigated the effects of the milk-derived peptides VPP and IPP on arterial function and target organ damage in rats chronically treated with L-NAME and revealed that VPP and IPP attenuated the decrease in acetylcholine-induced vasorelaxation, the increase in PWV and cardiac and/or renal damage in vivo.

The endothelium regulates vascular tone, platelet activity, leukocyte adhesion and angiogenesis by producing $\mathrm{NO}$ and other regulatory factors. ${ }^{1}$ Much attention has been paid to vascular endothelial function because it has the potential to serve as an early surrogate marker of CV events. ${ }^{20}$ In this study, the acetylcholine-induced vasorelaxation of aortic rings was significantly reduced by chronic L-NAME treatment, and the maximal relaxation after 4 weeks of treatment was less than the maximal relaxation after 1 week of treatment, which indicates that arterial function worsened over time when rats were treated with L-NAME. VPP and IPP prevented the reduction in vasorelaxation, even after 4 weeks of treatment. Hirota et al. ${ }^{10}$ reported that 1 week of treatment with casein hydrolysate containing VPP and IPP improved endothelial function, but not medial function, in hypertensive subjects. These findings suggest that 

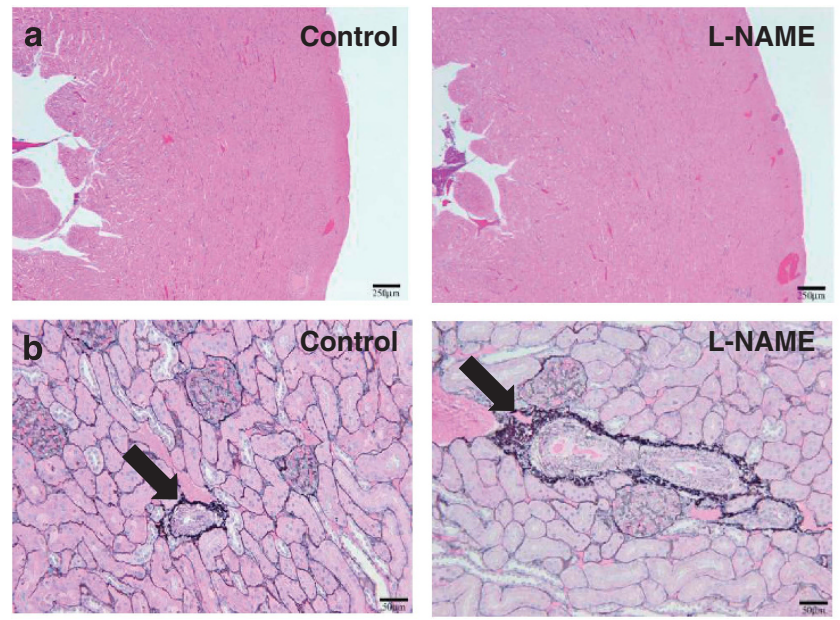
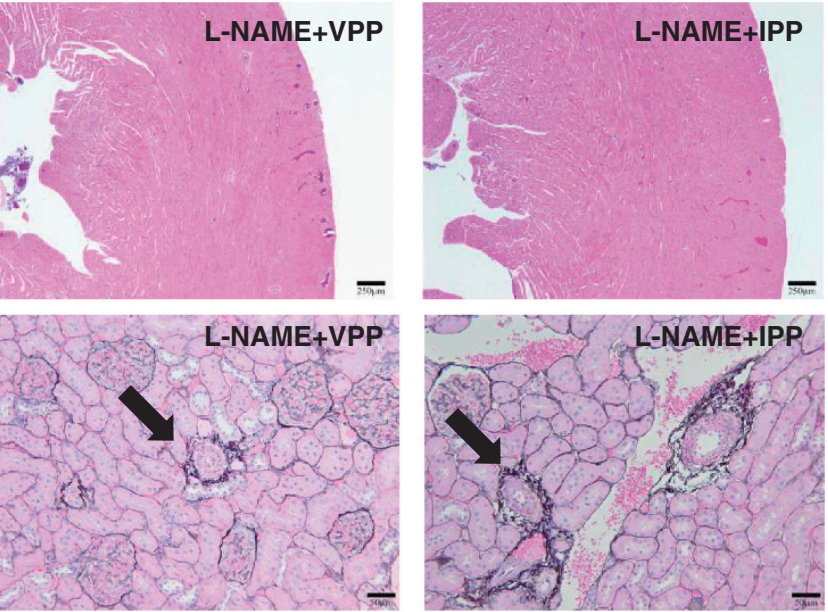

Figure 4 Representative sections of stained tissues in L-NAME-treated rats at 8 weeks. (a) Left ventricular wall (HE stain) and (b) renal histology (PAM stain). Arrows show the small-to-medium-sized arteries.

VPP and IPP could improve vascular endothelial function and would be beneficial in preventing vascular damage.

PWV is a well-accepted method for the measurement of arterial stiffness and has an independent predictive value for CV events. ${ }^{2}$ In this study, L-NAME treatment gradually increased PWV over time from $460.0 \mathrm{~cm} \mathrm{~s}^{-1}$ after 1 week to $572.9 \mathrm{~cm} \mathrm{~s}^{-1}$ after 4 weeks of treatment. In contrast, 4 weeks of treatment with VPP or IPP significantly attenuated the increase in PWV. This result is in agreement with a previous 8-week study that evaluated the intake of food containing VPP and IPP, which improved PWV in hypertensive subjects. ${ }^{11}$ In our study, 1 week of treatment with VPP or IPP improved endothelial function, but not PWV. Fitch et al. ${ }^{17}$ stated that endothelial dysfunction is observed early in atherosclerosis and may be a precursor to increased vascular stiffness. Blood pressure is a major determinant of endothelial dysfunction and arterial stiffness, ${ }^{21}$ but the blood pressure values did not differ in $\mathrm{L}-\mathrm{NAME}+\mathrm{VPP}$ and L-NAME + IPP groups when compared with the L-NAME group. Elevated blood pressure in L-NAME-treated hypertensive rats was found to be influenced mainly by the sympathetic nervous system rather than the renin-angiotensin system, ${ }^{22}$ which may explain why we did not observe changes in blood pressure with VPP or IPP treatment. Another reason could be that the blood pressure was measured under anesthesia in this study. Kameyama et al. ${ }^{18}$ reported that 3 weeks of treatment with L-NAME increased PWV and the wall-to-lumen ratio of the thoracic aorta in rats and that treatment with L-NAME + ACE inhibitor reduced both PWV and the thickness of the aortic wall. We did not evaluate the effects of VPP and IPP on structural changes in the aortic wall and PWV simultaneously, but the wall thickness of the small-to-mediumsized arteries of the kidney was attenuated with VPP or IPP after 8 weeks of treatment in this study. Moreover, in a previous study, chronic treatment with VPP and/or IPP attenuated atherogenesis in the aortae of apoE( $-/-)$ mice. ${ }^{8}$ Taken together, these findings and the results of this study suggest that there may be a possibility that VPP and IPP influence not only functional changes but also structural changes in the arteries, independent of blood pressure.

This study showed that either VPP or IPP can increase the plasma levels of NOx in normal Wistar rats. These peptides have ACE inhibitory activities, ${ }^{6}$ which suggests two possible mechanisms for the increase in NOx: (1) the bradykinin-potentiating effect activates NO production through the bradykinin $\mathrm{B} 2$ receptor $^{23}$ and (2) the decrease in angiotensin-II increases NO production due to a decrease in superoxide production. ${ }^{24}$ Our preliminary results showed that VPP and IPP promoted endothelial NOS (eNOS) phosphorylation in HUVECs (data not shown). In addition, it has been reported that L-NAME downregulates expression of eNOS mRNA and that ACE inhibitors enhanced the levels of eNOS mRNA, ${ }^{15,16}$ eNOS activation $^{25}$ and NO production. ${ }^{16,26}$ Yamaguchi et al. ${ }^{27}$ showed that VPP and IPP upregulate the expression of eNOS mRNA in the aortae of SHR. These findings support the idea that VPP and IPP increase NO production by regulation of eNOS expression and activation.

In contrast, VPP and IPP attenuated endothelial dysfunction, arterial stiffness and target organ damage despite the fact that there was no increase in plasma NOx concentration in L-NAME-treated rats. Hirota et al..$^{9}$ reported that VPP and IPP increased NOx concentration in human umbilical vein endothelial cell culture media after acetylcholine-induced vasorelaxation of isolated aortae. They also found that the vasorelaxant effect was reversed by L-NAME (NOS inhibitor), HOE 140 (antagonist of bradykinin B2 receptor) and TEA ( $\mathrm{K}^{+}$channel inhibitor), but not by indomethacin, an inhibitor of prostaglandin synthesis. The bradykinin B2 receptor regulates the production of endothelium-derived relaxants, such as $\mathrm{NO}$ and endothelium-derived hyperpolarizing factor (EDHF). Although the identity of EDHF has been not yet determined, reported candidates include epoxy eicosatrienoic acid and hydrogen peroxide $\left(\mathrm{H}_{2} \mathrm{O}_{2}\right)$. In addition, TEA is considered to inhibit EDHF action, ${ }^{28}$ although it is a non-selective $\mathrm{K}^{+}$channel inhibitor and inhibits not only $\mathrm{KCa}$ channels but also other $\mathrm{K}^{+}$channels. Therefore, the vasoprotective effects of VPP and IPP might be related to the activities of $\mathrm{NO}$ and EDHF. Further mechanistic studies on the vasoprotective effects of VPP and IPP are needed.

In this study, rats received $0.3 \mathrm{gl}^{-1}$ (approximately $30 \mathrm{mg} \mathrm{kg}^{-1}$ per day) VPP or IPP dissolved in drinking water. The amount of VPP or IPP is much higher than the human daily dose of 3-7 mg of VPP + IPP used in previous clinical trials. ${ }^{10,11}$ Therefore, it is difficult to extrapolate the results of this study to humans because of the differences in species and in bioavailability. However, in previous clinical trials, arterial functions such as endothelial function ${ }^{10}$ and arterial stiffness ${ }^{11}$ were significantly improved by supplementation of the diet with casein hydrolysate containing VPP and IPP, which 
supports the results of this study and the idea that VPP and IPP may prevent vascular damage even in humans.

In conclusion, we confirmed that VPP and IPP each prevented vascular endothelial dysfunction, arterial stiffness and target organ damage in L-NAME-treated rats. These results suggest that continuous intake of food containing VPP or IPP might have clinical significance and that such a lifestyle modification could prevent vascular damage and CV events.

\section{CONFLICT OF INTEREST}

AN, TN, TH, AM, and KO are employed as research scientists by Calpis. The remaining authors declare no conflict of interest.

1 Vita JA. Endothelial function. Circulation 2011; 124: e906-e912.

2 Laurent S, Cockcroft J, Van Bortel L, Boutouyrie P, Giannattasio C, Hayoz D, Pannier B, Vlachopoulos C, Wilkinson I, Struijker-Boudier HEuropean Network for Non-invasive Investigation of Large Arteries. Expert consensus document on arterial stiffness: methodological issues and clinical applications. Eur Heart J 2006; 27: 2588-2605

3 Vlachopoulos C, Aznaouridis K, Stefanadis C. Prediction of cardiovascular events and all-cause mortality with arterial stiffness: a systematic review and meta-analysis. J Am Coll Cardiol 2010; 55: 1318-1327.

4 Pizzi C, Manfrini O, Fontana F, Bugiardini R. Angiotensin-converting enzyme inhibitors and 3-hydroxy-3-methylglutaryl coenzyme A reductase in cardiac Syndrome X: role of superoxide dismutase activity. Circulation 2004; 109: 53-58.

5 Pase MP, Grima NA, Sarris J. The effects of dietary and nutrient interventions on arterial stiffness: a systematic review. Am J Clin Nutr 2011: 93: 446-454.

6 Nakamura Y, Yamamoto N, Sakai K, Okubo A, Yamazaki S, Takano T. Purification and characterization of angiotensin I-converting enzyme inhibitors from sour milk. J Dairy Sci 1995; 78: 777-783.

7 Nakamura Y, Yamamoto N, Sakai K, Takano T. Antihypertensive effect of sour milk and peptides isolated from it that are inhibitors to angiotensin I-converting enzyme. J Dairy Sci 1995; 78: 1253-1257.

8 Nakamura T, Hirota T, Mizushima K, Ohki K, Naito Y, Yamamoto N, Yoshikawa T. Milk-derived peptides, Val-Pro-Pro and Ile-Pro-Pro, attenuate atherosclerosis development in apolipoprotein e-deficient mice: a preliminary study. J Med Food 2013; 16: 396-403

9 Hirota T, Nonaka A, Matsushita A, Uchida N, Ohki K, Asakura M, Kitakaze M. Milk casein-derived tripeptides, VPP and IPP induced NO production in cultured endothelial cells and endothelium-dependent relaxation of isolated aortic rings. Heart Vessels 2011; 26: 549-556.

10 Hirota T, Ohki K, Kawagishi R, Kajimoto Y, Mizuno S, Nakamura Y, Kitakaze M. Casein hydrolysate containing the antihypertensive tripeptides Val-Pro-Pro and Ile-Pro-Pro improves vascular endothelial function independent of blood pressure-lowering effects: contribution of the inhibitory action of angiotensin-converting enzyme. Hypertens Res 2007; 30: 489-496.

11 Nakamura T, Mizutani J, Ohki K, Yamada K, Yamamoto N, Takeshi M, Takazawa K. Casein hydrolysate containing Val-Pro-Pro and Ile-Pro-Pro improves central blood pressure and arterial stiffness in hypertensive subjects: a randomized, double-blind, placebo-controlled trial. Atherosclerosis 2011; 219: 298-303.

12 Raji L. Vascular and renal nitric oxide. In: Izzo JL, Sica DA and Black HR (eds). Hypertension Primer: The Essentials of High Blood Pressure: Basic Science,
Population Science, and Clinical Management, 4th edn. Lippincott Williams \& Wilkins Philadelphia, PA, USA, 2008, pp 78-82.

13 Rees DD, Palmer RM, Schulz R, Hodson HF, Moncada S. Characterization of three inhibitors of endothelial nitric oxide synthase in vitro and in vivo. Br J Pharmacol 1990; 101: 746-752.

14 Dornas WC, Silva ME. Animal models for the study of arterial hypertension. J Biosci 2011; 36: 731-737.

15 De Gennaro Colonna V, Rossoni G, Rigamonti A, Bonomo S, Manfredi B, Berti F, Muller E. Enalapril and quinapril improve endothelial vasodilator function and aortic eNOS gene expression in L-NAME-treated rats. Eur J Pharmacol 2002; 450: 61-66.

16 De Gennaro Colonna V, Rigamonti A, Fioretti S, Bonomo S, Manfredi B, Ferrario P, Bianchi M, Berti F, Muller EE, Rossoni G. Angiotensin-converting enzyme inhibition and angiotensin AT1-receptor antagonism equally improve endothelial vasodilator function in L-NAME-induced hypertensive rats. Eur J Pharmacol 2005; 516: 253-259.

17 Fitch RM, Vergona R, Sullivan ME, Wang YX. Nitric oxide synthase inhibition increases aortic stiffness measured by pulse wave velocity in rats. Cardiovasc Res 2001; 51: 351-358.

18 Kameyama H, Takeda K, Kusaba T, Narumiya H, Tanda S, Kuwahara N, Yamada K, Tamagaki K, Okigaki M, Hatta T, Sasaki S. Augmentation of pulse wave velocity precedes vascular structural changes of the aorta in rats treated with $\mathrm{N}$ (omega)-nitro-Larginine methyl ester. Hypertens Res 2005; 28: 439-445.

19 Sanada S, Kitakaze M, Node K, Takashima S, Ogai A, Asanuma H, Sakata Y, Asakura M, Ogita H, Liao Y, Fukushima T, Yamada J, Minamino T, Kuzuya T, Hori M. Differential subcellular actions of ACE inhibitors and AT(1) receptor antagonists on cardiac remodeling induced by chronic inhibition of NO synthesis in rats. Hypertension 2001; 38: 404-411.

20 Green DJ, Jones H, Thijssen D, Cable NT, Atkinson G. Flow-mediated dilation and cardiovascular event prediction: does nitric oxide matter? Hypertension 2011; 57: 363-369.

21 Lilitkarntakul P, Dhaun N, Melville V, Blackwell S, Talwar DK, Liebman B, Asai T, Pollock J, Goddard J, Webb DJ. Blood pressure and not uraemia is the major determinant of arterial stiffness and endothelial dysfunction in patients with chronic kidney disease and minimal co-morbidity. Atherosclerosis 2011; 216: 217-225.

22 Pechánová O, Dobesová Z, Cejka J, Kunes J, Zicha J. Vasoactive systems in L-NAME hypertension: the role of inducible nitric oxide synthase. J Hypertens 2004; 22: 167-173.

23 Cargnoni A, Comini L, Bernocchi P, Bachetti T, Ceconi C, Curello S, Ferrari R. Role of bradykinin and eNOS in the anti-ischaemic effect of trandolapril. $\mathrm{Br} \mathrm{J}$ Pharmacol 2001; 133: 145-153.

24 Rajagopalan S, Kurz S, Münzel T, Tarpey M, Freeman BA, Griendling KK, Harrison DG. Angiotensin II-mediated hypertension in the rat increases vascular superoxide production via membrane NADH/NADPH oxidase activation. Contribution to alterations of vasomotor tone. J Clin Invest 1996; 97: 1916-1923.

25 Donnini S, Terzuoli E, Ziche M, Morbidelli L. Sulfhydryl angiotensin-converting enzyme inhibitor promotes endothelial cell survival through nitric-oxide synthase, fibroblast growth factor-2, and telomerase cross-talk. J Pharmacol Exp Ther 2010; 332: 776-784.

26 Kitakaze M, Node K, Takashima S, Minamino T, Kuzuya T, Hori M. Cellular mechanisms of cardioprotection afforded by inhibitors of angiotensin converting enzyme in ischemic hearts: role of bradykinin and nitric oxide. Hypertens Res 2000; 23: 253-259.

27 Yamaguchi N, Kawaguchi K, Yamamoto N. Study of the mechanism of antihypertensive peptides VPP and IPP in spontaneously hypertensive rats by DNA microarray analysis. Eur J Pharmacol 2009; 620: 71-77.

28 Campbell WB, Gebremedhin D, Pratt PF, Harder DR. Identification of epoxyeicosatrienoic acids as endothelium-derived hyperpolarizing factors. Circ Res 1996; 78: 415-423. 